\title{
Reversal learning in an escape situation
}

JOHN T. WILLIAMS, JR, AND MICHAEL H. SCOTT, DEPARTMENT OF PSYCHOLOGY, UNIVERSITY OF SOUTH CAROLINA, Columbia, S. C. 29208

Rats were trained on a series of successive, spatial habit reversals with shock escape for reinforcement and criteria of either of 6 or 12 consecutive correct trials per problem. There was a tendency, particularly with the less stringent criterion, for the Ss to regress after having reached a point of single-error reversing. A possible explanation based upon motivational level was given for this regression.

In successive reversal learning situations, rats almost invariably demonstrate progressive improvement across reversals, and they often learn to reverse after a single error on each problem (e.g., Dufort, Guttman, \& Kimble, 1954; Pubols, 1957). In these experiments, rats were trained on a series of spatial discrimination problems with food reward and reached single error reversal proficiency within 10 reversals. Pubols (1962) has also shown that rats with a greater number of trials per problem tend to make more errors on the first few reversals and then improve at a faster rate than do rats with fewer trials per problem. This tendency to make more errors early in training with greater training on each reversal is generally considered to result from greater negative transfer.

In one of the few studies of reversal learning in vertebrates using escape from noxious stimulation as reinforcement, Williams (1968) found that caimans (reptiles related to alligators) showed an improvement during the first few reversals which was followed by a regression and then a second improvement. Also, caimans with a criterion of 12 consecutive correct trials showed overall improvement across 20 reversals, but caimans with a criterion of only six consecutive correct did not improve over their original, but rather efficient, level of performance. The present study was conducted to determine whether rats would also regress from a plateau of maximum efficiency when escape from a clearly noxious shock was used for reinforcement.

Subjects. Sixteen naive, female albino rats served as Ss. They were about 140 days of age at the beginning of the experiment and were fed on an ad lib basis except during each day's testing session.

Apparatus. The apparatus was a modified T-maze with galvanized metal sides and a floor made of 1 in. wide stainless steel plates, running diagonally, and separated by $1 / 8$ in. spaces. A metal guillotine door converted the incorrect arm of the $\mathrm{T}$ into a cul-de-sac, and a bend in each arm prevented the $\mathrm{S}$ from seeing the cul or the goal box from the choice point. The goal box had a floor depressed 2 in. below grid level and covered with absorbent paper which was changed periodically. A $30 \mathrm{~V}$ ac shock was delivered to the floor and sides of the maze through a 16-outlet shock scrambler. The maze was covered with clear plastic so that the Ss could not jump out the top. Diagrams and dimensions of the maze have been presented elsewhere (Williams, 1967, 1968).

Procedure. On a given trial, the $S$ was removed from its cage and dropped onto the grid at the base of the $T$ facing the choice point. Since shock escape was used, a correction procedure was necessary. Ten sec after the $S$ entered the goal box, it was removed and returned to its cage. Each $S$ received 15 trials per day with an intertrial interval of $8-15 \mathrm{~min}$.

The Ss were randomly divided into two groups of eight Ss each. The Ss in Group $C=6$ were reversed every time they responded correctly on six consecutive trials, and those in Group $C=12$ had a criterion of 12 consecutive correct. Half of the Ss in each group were trained to turn to the right on the first problem, and half were trained to the left. Each $S$ in Group $\mathrm{C}=12$ learned at least 18 reversals, and each $\mathrm{S}$ in Group $\mathrm{C}=6$ learned at least 30.

Results. The mean numbers of errors per reversal, averaged across pairs of reversals to eliminate any effects produced by possible position preferences, are shown in Fig. 1. An analysis of variance of these data for nine pairs of reversals indicated that the difference between groups was highly significant $(F=55.83, \mathrm{df}=$

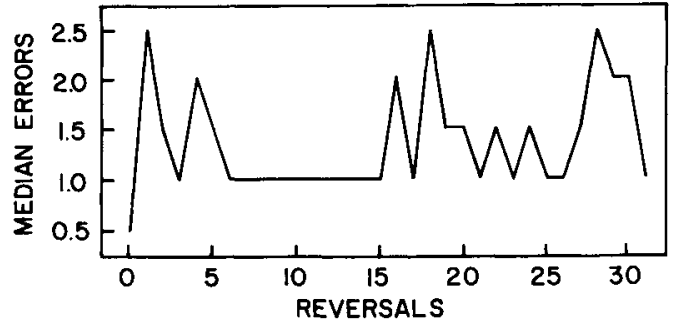

Fig. 2. Median number of errors on each problem for Group $C=6$.

$1 / 14, \mathrm{p}<.001)$ as was the reversals effect $(\mathrm{F}=4.37, \mathrm{df}=8 / 112, \mathrm{p}$ $<.001)$. The interaction between groups and reversals was marginally significant $(\mathrm{F}=1.84, \mathrm{df}=8 / 112, \mathrm{p}<.10)$. Orthogonal tests for trend indicated that there was a highly significant linear component in Group $\mathrm{C}=12(\mathrm{~F}=17.29, \mathrm{~d} f=1 / 56, \mathrm{p}<.001)$ and also significant quadratic $(F=5.14$, df $=1 / 56, p<.05)$ and quintic components $(\mathrm{F}=6.87, \mathrm{df}=1 / 56, \mathrm{p}<.05)$. In Group $\mathrm{C}=$ 6 , only the quadratic component was significant $(F=32.14$, df $=$ $1 / 56, p<.001)$. It may be noted that the curve for Group $\mathrm{C}=6$ clearly falls then rises again in Fig. 1. (With additional testing, there was a second drop and still another rise.)

The median numbers of errors per problem throughout training for Group $C=6$ is given in Fig. 2. Single error learning was significantly more frequent during the first 16 problems than during the last 16 problems $\left(x^{2}=4.57, \mathrm{df}=1, \mathrm{p}<.05\right)$.

Discussion. The behavior of the Ss in Group $C=12$ is basically what one would expect in this situation. The increase in errors on the first reversal followed by a decrease across subsequent reversals, as indicated by the significant linear trend component, is an almost universal finding with higher vertebrates (Bitterman, 1965). However, the performance on the first problem by both groups was rather surprising. Seven $S s$ did not make a single error (chance training toward their preferred side?), seven made a single error, and the other two made two errors each. This single-error learning on the first problem raises some interpretive difficulties for anyone who views single-error reversals as evidence for some form of set learning.

Even if the first problem is overlooked, the question remains as to why the Ss in Group $C=6$ did not improve overall across reversals. One could argue that a criterion of only six consecutive correct trials was not sufficient for a well developed habit to develop on each problem, but the extremely efficient behavior of most of the Ss, as indicated in Fig. 2, seems to offset this argument. Bullock \& Bitterman (1962) have suggested that Ss may not improve across reversals if they are insufficiently motivated. Perhaps this is a two-pronged argument. An S performing at maximum efficiency in Group C

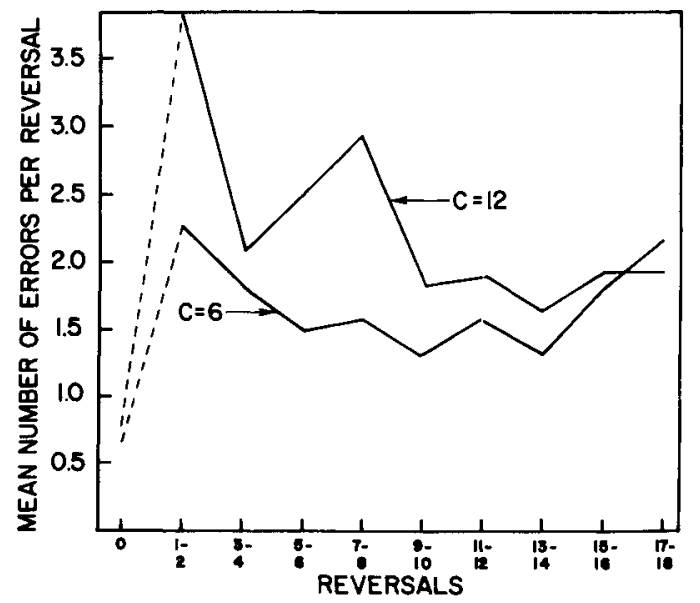

Fig. 1. Mean number of errors per reversal, averaged across pairs of reversals. (Reversal-0 represents the original problem.) 
$=6$ would make an incorrect turn every seventh trial, or once after each reversal. If the motivational level were sufficiently high to make the consequences of an error extremely noxious, an $\mathbf{S}$ might be expected to desert a win-stay, lose-shift strategy based upon position in an attempt to eliminate all errors. Since other patterns of responding would produce more errors, the $\mathrm{S}$ would be expected to return to its earlier, maximally efficient, strategy. This explanation appears to be consistent with the data. Frequently, an individual $S$ would perform seven or eight single-error reversals, four or five reversals with about three errors each, then return to "perfect" performance for several days. Since these regressions occurred at different times for different $\mathrm{Ss}$, the net result was an oscillation in performance during the later stages of testing.

The foregoing explanation is still in the realm of speculation. It would be quite helpful to test rats with food reward to determine whether, after having demonstrated single-error reversing, they would regress with prolonged testing as have rats and caimans in a shock escape situation.

\section{REFERENCES}

BITTERMAN, M. E. Phyletic differences in learning. Amer. Psychologist, $1965,20,396410$.

BULLOCK, D. H., \& BITTERMAN, M. E. Habit reversal in the pigeon. $J$. comp. physiol. Psychol., 1962, 55, 958-962.

DUFORT, R. H., GUTTMAN, N., \& KIMBLE, G. A. One-trial discrimination reversal in the white rat. $J$. comp. physiol. Psychol., 1954, 47, 248-249.

PUBOLS, B. H. Successive discrimination reversal learning in the white rat: A comparison of two procedures. J. comp. physiol. Psychol., 1957, 50, 319-322.

PUBOLS, B. H. Serial reversal learning as a function of the number of trials per reversal. J. comp. physiol Psychol., 1962, 55, 66-68.

WILLIAMS, J. T., Jr. A test for dominance of cues during maze learning by toads. Psychon. Sci., 1967, 9, 259-260.

WILLIAMS, J. T., Jr. Reversal-learning in the spectacled caiman. Amer. $J$. Psychol, 1968, in press. 